\title{
geFORSETI
}

Forseti. Revista de Derecho. Edición de aniversario, Lima, DERUP, 2018, pp 100-117

\section{¿Cuándo nos encontramos ante un laudo arbitral firme?}

\author{
Ana María Arrarte Arisnabarreta* \\ Sheilah Vargas Soto
}

Resumen.- En el presente artículo, las autoras a la luz de lo dispuesto en la Ley de Arbitraje sobre los efectos y ejecutividad del laudo, intentan dilucidar cuando nos encontramos frente a un laudo arbitral firme. Además, analizan los supuestos en los que el laudo arbitral puede adquirir firmeza.

Abstract.- As a consequence of the regulation of the Arbitration Law, referring to the effects and enforceability of the arbitral award; the authors elaborate when a binding arbitration award occurs. As well as the circumstances in which the arbitration award can acquire firmness.

\footnotetext{
Socia Principal del Estudio Echecopar asociado a Baker Mckenzie Internacional. Líder del Área de Litigios y Solución de Arbitrajes del Estudio Echecopar. Abogada por la Universidad de Lima. Árbitro en diversas instituciones arbitrales. Se ha desempañado profesora de pregrado en la materia Derecho Procesal en la Universidad de Lima, la Pontificia Universidad Católica del Perú, la Universidad del Pacífico, y como profesora de post grado en la maestría de Derecho Procesal de la Universidad de Ciencias Aplicadas -UPC.

** Magister en Relaciones Internacionales y Protección Internacional de los Derechos Humanos por la Sociedad Italiana de las Organizaciones Internacionales (SIOI), Roma. Abogada por la Pontificia Universidad Católica del Perú. Árbitro en diversas instituciones arbitrales. Asociada Principal del Área de Litigios y Solución de Arbitrajes del Estudio Echecopar.
} 


\section{Introducción}

Para el presente artículo tratará de determinar cuándo nos encontramos ante un laudo arbitral firme; ello, a propósito de los casos en que se concluye un arbitraje y las partes han pactado en el convenio arbitral que las garantías que se hubieran otorgado durante el proceso se mantienen vigentes hasta que se cuente con un laudo firme, o de los casos en los que se emite el laudo arbitral y, sin embargo, la parte vencida obtiene una medida cautelar que suspende sus efectos.

Para ello, consideramos fundamental el análisis que debe realizarse al artículo 59 del Decreto Legislativo No. 1071, Ley de Arbitraje (en adelante, la «LA» $)^{1}$, que se refiere a los efectos del laudo y a la ejecutividad del mismo.

Como podrá apreciarse, la norma en cuestión señala que el laudo arbitral surte efectos desde que es notificado a las partes y, por tanto, puede ser ejecutable desde ese momento. Sin embargo, lo que dicha norma no regula es desde cuándo debe entenderse que un laudo adquiera la calidad de firme y que, por tanto, produce los efectos de la autoridad de la cosa juzgada o, excepcionalmente, a través de un proceso de amparo ${ }^{2}$.

La definición de la calidad de firme es relevante en la medida que puede darse el caso que un laudo arbitral tenga la calidad de ejecutable (eficaz), y que dicho laudo pueda ser materia de impugnación por la parte afectada a través de un recurso de anulación.

En efecto, debe recordarse que la actual LA -a diferencia de la anterior Ley General de Arbitraje, Ley 26572- ha establecido como regla la ejecución inmediata de los laudos, ya que el recurso de anulación no suspende la eficacia del laudo, salvo que se haya prestado algún tipo

1 «Artículo 59.- Efectos del laudo.

1. Todo laudo es definitivo, inapelable y de obligatorio cumplimiento desde su notificación a las partes.

2. El laudo produce efectos de cosa juzgada.

3. Si la parte obligada no cumple con lo ordenado por el laudo, en la forma y en los plazos establecidos, o en su defecto, dentro de los quince (15) días de notificada con el laudo o con las rectificaciones, interpretaciones, integraciones y exclusiones del laudo, cuando corresponda; la parte interesada podrá pedir la ejecución del laudo a la autoridad judicial competente, salvo que resulte aplicable el artículo 67».

2 Como consta en el Caso Minera María Julia, sentencia recaída en el Expediente No. 001422001-PA/TC. 
de garantía con este propósito, conforme a los términos previstos en el artículo 66 de la LA3.

En tal sentido, a continuación, analizaremos el contenido de dicha norma determinando los alcances de los conceptos «definitivo», «ejecutable» $\mathrm{y}$ «firme» vinculados a las resoluciones arbitrales.

\section{II. ¿Cuándo nos encontramos ante una Resolución firme?}

Una de las características de la función jurisdiccional es la aptitud para resolver las controversias e incertidumbres jurídicas, contando además con la autoridad de cosa juzgada, y como tal, son decisiones inmutables y definitivas ${ }^{4}$.

Como primer tema, debemos diferenciar dos conceptos o calidades que recaen sobre las decisiones jurisdiccionales: (i) definitiva y (ii) firme.

3 «Artículo $66^{\circ}$.- Garantía de cumplimiento.

1. La interposición del recurso de anulación no suspende la obligación de cumplimiento del laudo ni su ejecución arbitral o judicial, salvo cuando la parte que impugna el laudo solicite la suspensión y cumpla con el requisito de la garantía acordada por las partes o establecida en el reglamento arbitral aplicable. Al examinar la admisión del recurso, la Corte Superior verificará el cumplimiento del requisito y, de ser el caso, concederá la suspensión. (...)

Similar disposición la encontramos en el artículo 45 de la Ley de Arbitraje Española:

Artículo 45.- Suspensión, sobreseimiento y reanudación de la ejecución en caso de ejercicio de la acción de anulación.

1. El laudo es ejecutable aun cuando contra él se haya ejercitado acción de anulación. No obstante, en ese caso el ejecutado podrá solicitar al tribunal competente la suspensión de la ejecución, siempre que ofrezca caución por el valor de la condena más los daños y perjuicios que pudieren derivarse de la demora en la ejecución del laudo. La caución podrá constituirse en cualquiera de las formas previstas en el párrafo segundo del apartado 3 del artículo 529 de la Ley de Enjuiciamiento Civil. Presentada la solicitud de suspensión, el tribunal, tras oír al ejecutante, resolverá sobre la caución.

Contra esta resolución no cabrá recurso alguno.

2. El Secretario judicial alzará la suspensión y ordenará que continúe la ejecución cuando conste al Tribunal la desestimación de la acción de anulación, sin perjuicio del derecho del ejecutante a solicitar, en su caso, indemnización de los daños y perjuicios causados por la demora en la ejecución, a través de los cauces ordenados en los artículos 712 y siguientes de la Ley de Enjuiciamiento Civil.

3. El Secretario judicial alzará la ejecución, con los efectos previstos en los artículos 533 y 534 de la Ley de Enjuiciamiento Civil, cuando conste al Tribunal que ha sido estimada la acción de anulación.

Si la anulación afectase sólo a las cuestiones a que se refiere el apartado 3 del artículo 41 y subsistiesen otros pronunciamientos del laudo, se considerará estimación parcial, a los efectos previstos en el apartado 2 del artículo 533 de la Ley de Enjuiciamiento Civil» (énfasis es nuestro)».

4 En este contexto, vale citar a Carnelutti, que distinguía entre imperatividad e inmutabilidad de la sentencia. «La primera, convendría a la sentencia como tal y la segunda a la venida en autoridad de cosa juzgada». Citado por ORMAZABAL SÁNCHEZ, Guillermo. La ejecución de laudos arbitrales. Barcelona, J.M. Bosch, 1996, p. 44. 
Nos encontramos ante una decisión definitiva, cuando el órgano jurisdiccional emite la sentencia resolviendo el conflicto de intereses que le fue sometido por las partes 5 . En palabras de Devis Echandía:

Es el acto por el cual el juez cumple la obligación jurisdiccional derivada de la acción y del derecho de contradicción, de resolver sobre las pretensiones del demandante y las excepciones de mérito o fondo del demandado ${ }^{6}$.

Una vez que se emite la decisión definitiva (sea sentencia o laudo arbitral) se produce un lapso denominado «estado de gravamen», que es entendido como el periodo en que dicha decisión puede ser cuestionada por la parte que se considera agraviada con la misma, a través de un medio impugnatorio (medio de gravamen).

$\mathrm{Al}$ respecto, Calamandrei señala lo siguiente:

La posibilidad de obtener una segunda sentencia en una relación ya decidida una vez, está condicionada a la petición de la parte, y limitada dentro de un término perentorio; la parte tiene así, dentro de este término, un derecho de gravamen, que puede definirse como el derecho (derecho potestativo existente por sí, e independiente, como se verá, de la existencia de un vicio de la sentencia) de determinar el nacimiento de la condición para pasar del examen anterior a un ulterior examen de la misma relación controvertida. Medio de gravamen es el ejercicio de ese derecho. CHIOVENDA define, en efecto, la apelación, que es el medio de gravamen típico, como el medio para pasar del primero al segundo grado de jurisdicción 7 .

Por tanto, una decisión definitiva es pasible de ser impugnada por el titular que se considere afectado con ella.

Por otro lado, nos encontramos ante una resolución firme, en los casos en que la decisión emitida por el órgano jurisdiccional no pueda ser cuestionada ya por los mecanismos previstos para su revisión.

Y ello puede ocurrir por dos situaciones: (i) porque la parte interesada en cuestionar la decisión dejó vencer el plazo para interponer el mecanismo impugnatorio sin plantearlo (lo que se denomina

5 Este tipo de sentencia es la que se conoce en doctrina como sentencia material o fondal, frente a las sentencias inhibitorias (que se pronuncian sobre la invalidez de la relación jurídica procesal).

6 Este tipo de sentencia es la que se conoce en doctrina como sentencia material o fondal, frente a las sentencias inhibitorias (que se pronuncian sobre la invalidez de la relación jurídica procesal).

7 CALAMANDREI, Piero. Estudios sobre el Proceso Civil. Buenos Aires, Bibliográfica Argentina, 1961, pp. 440-441. 
como resolución consentida), o (ii) porque ya utilizó todos los medios impugnatorios previstos en la ley para revertir el agravio que le ocasionaba tal decisión (resolución ejecutoriada).

\section{Respecto a este tema, Devis Echandía señala que:}

Ésta (refiriéndose a la resolución firme) se cumple cuando no hay recursos pendientes por no otorgarlos la ley o por haber pasado el término para interponerlos, cualquiera que sea la sentencia; $(. .)^{8}$

Son las resoluciones firmes (consentidas o ejecutoriadas) las que pueden adquirir la autoridad de cosa juzgada ${ }^{9}$, volviéndose definitivas, inmutables y pasibles de ser ejecutada incluso de manera coercitiva, por parte del órgano jurisdiccional ${ }^{10}$. Cabe señalar que este carácter de cosa juzgada es una autoridad que es impuesta por una decisión de política legislativa, en aras de la seguridad jurídica ${ }^{11}$.

Por tanto, una decisión firme que adquiere la autoridad de cosa juzgada es irreversible e inmutable, además de ejecutable por las partes, surtiendo efectos frente a terceros respecto a lo decidido ${ }^{12}$.

8 DEVIS ECHANDÍA. Hernando. Teoría General del Proceso. Tomo II. Buenos Aires, Editorial Universidad, 1999, pp. 523-524.

9 Al respecto, Devis Echandía señala: «(...) cosa juzgada como la calidad de inmutable y definitiva que la ley otorga a la sentencia y a algunas otras providencias que sustituyan aquella, en cuanto declara la voluntad del Estado contenida en la norma legal que aplica en el caso concreto». En: DEVIS ECHANDÍA, Hernando. Op. cit., p. 562.

10 «Artículo 123.- Cosa Juzgada

Una resolución adquiere la autoridad de cosa juzgada cuando:

1. No proceden contra ella otros medios impugnatorios que los ya resueltos; o

2. Las partes renuncian expresamente a interponer medios impugnatorios o dejan transcurrir los plazos sin formularlos.

La cosa juzgada sólo alcanza a las partes y a quienes de ellas deriven sus derechos. Sin embargo, se puede extender a los terceros cuyos derechos dependen de los de las partes o a los terceros de cuyos derechos dependen los de las partes, si hubieran sido citados con la demanda.

La resolución que adquiere la autoridad de cosa juzgada es inmutable, sin perjuicio de lo dispuesto en los Artículos 178 y 407».

11 Al respecto, Couture indica: «La cosa juzgada es, en resumen, una exigencia política y no propiamente jurídica: no es una razón natural, sino una exigencia práctica». En: COUTURE, Eduardo. Fundamentos de Derecho Procesal Civil. Buenos Aires, Roque Depalma, 1958, pp. 405-407. Por su parte, Liebman señala lo siguiente: «Autoridad de la cosa juzgada no se refiere a un efecto autónomo, indica por el contrario la fuerza, el modo con que ciertos efectos se producirán, esto es, una cualidad o modo de ser tales efectos». En: LIEBMAN, Tullio. Eficacia y Autoridad de la sentencia. Buenos Aires, Eidar, 1946, pp. 20-21.

12 Al respecto, MONTERO AROCA señala lo siguiente:

(...) la expresión «cosa juzgada» se emplea por la doctrina y se consigna en la Ley tanto para hacer referencia a «cosa juzgada formal» como para aludir a «cosa juzgada material», distinguiéndose la primera por ser un efecto interno de la resolución, referido, al proceso en el que recae, que impide que pueda ser ignorada o desconocida en el posterior desarrollo del mismo, (...), al tiempo que la segunda despliega sus efectos fuera del proceso mismo en el que la resolución se dicta, alcanzando a otro proceso distinto y posterior y comporta la vinculación en este otro proceso a lo decidido en el primero sobre la pretensión misma. 
Finalmente, debemos señalar que contra las decisiones jurisdiccionales que adquieren la autoridad de cosa juzgada, nuestro ordenamiento jurídico ha previsto mecanismos excepcionales de control (distintos a los medios impugnatorios o recursos que se pueden plantear en un proceso determinado) como son el proceso de nulidad de cosa juzgada fraudulenta ${ }^{13} \mathrm{o}$ el proceso de amparo ${ }^{14}$, que constituyen procesos autónomos con pretensiones impugnatorias que tienen por objeto declarar la nulidad de la sentencia que ya adquirió la autoridad de cosa juzgada, alegando para ello que ha sido emitida mediando fraude procesal ${ }^{15} \mathrm{o}$ vicios graves de afectación a derechos fundamentales.

Nótese que el momento en el que una decisión adquiere la calidad de firme es aquél en el que el ordenamiento jurídico le atribuye la autoridad de cosa juzgada. Los mecanismos excepcionales y residuales previstos en nuestro ordenamiento jurídico (nulidad de cosa juzgada fraudulenta y amparo) no determinan que la decisión no sea firme, tanto así que el propósito del proceso no será entrar a modificar lo decidido sino «levantar» esta autoridad (cosa juzgada) que reposa sobre una decisión viciada y lesiva al derecho de las partes y al sentido de justicia.

Veamos como aplicaría lo antes mencionado a los laudos arbitrales.

MONTERO, Juan. Citado por MERINO, José F. y CHILLÓN, José María. Tratado de Derecho Arbitral. Navarra, Thomson-Civitas, 2006, p. 666.

13 «Artículo 178.- Nulidad de Cosa Juzgada Fraudulenta

Hasta dentro de seis meses de ejecutada o de haber adquirido la calidad de cosa juzgada, si no fuere ejecutable puede demandarse, a través de un proceso de conocimiento la nulidad de una sentencia o la del acuerdo de las partes homologado por el Juez que pone fin al proceso, alegando que el proceso que se origina ha sido seguido con fraude, o colusión, afectando el derecho a un debido proceso, cometido por una, o por ambas partes, o por el Juez o por éste y aquellas (...) (énfasis es nuestro)».

14 «Artículo 44.- Plazo de interposición de la demanda

El plazo para interponer la demanda de amparo prescribe a los sesenta días hábiles de producida la afectación, siempre que el afectado hubiese tenido conocimiento del acto lesivo y se hubiese hallado en posibilidad de interponer la demanda. Si esto no hubiese sido posible, el plazo se computará desde el momento de la remoción del impedimento.

Tratándose del proceso de amparo iniciado contra resolución judicial, el plazo para interponer la demanda se inicia cuando la resolución queda firme. Dicho plazo concluye treinta días hábiles después de la notificación de la resolución que ordena se cumpla lo decidido (...) (énfasis nuestro)».

$15 \mathrm{Al}$ respecto, hemos señalado:

La pretensión principal en el proceso será la anulación de la sentencia y eventualmente del proceso o de parte de él por haberse demostrado la existencia de fraude. (...) La sentencia que declara fundada la demanda en este proceso, levanta la autoridad de cosa juzgada de la decisión definitiva, creando las condiciones para una nueva revisión. Ahora bien, si la sentencia anulada se dictó como producto de la influencia de otros actos viciados, lo que corresponde es retrotraer las cosas al estado anterior al que se produjo el fraude procesal, procediéndose a anular todos los actos afectados por tal conducta.

ARRARTE, Ana María. «Nulidad de Cosa Juzgada Fraudulenta». En: Materiales de Estudio de la Universidad Privada San Pedro. Facultad de Derecho y Ciencias Políticas, 1997, pp. 66-71. 


\section{III. ¿Cuándo nos encontramos ante un laudo arbitral firme?}

En principio, debemos precisar que la Constitución Política del Estado le otorga al arbitraje el carácter de «jurisdicción», conforme se aprecia de su artículo $139.1^{16}$. Y en ese sentido, también se ha pronunciado nuestro Tribunal Constitucional en la sentencia recaída en el Expediente No. 6167-2005-PHC/TC (Caso Cantuarias Salaverry) $)^{17}$.

Ahora bien, aplicando lo anteriormente expuesto respecto a la firmeza de las decisiones jurisdiccionales, tenemos lo siguiente:

El arbitraje, en tanto actividad jurisdiccional, goza de los mismos atributos que aquellos que regularmente son asociados a los procesos judiciales, por ello no hay impedimento alguno para aplicar el concepto de resolución definitiva y resolución firme a los laudos arbitrales. Así, respecto al carácter definitivo del laudo, hemos observado que el mismo se produce al momento de su notificación ${ }^{18}$, entendida ésta como la «irrevocabilidad por parte del órgano que dictó la resolución ${ }^{19}$, o de ser el caso, desde el momento en que se emiten las decisiones respecto a los pedidos de rectificación, integración y/o exclusión interpuestos contra el laudo, previstos en determinados ordenamientos jurídicos.

Respecto a la calidad de firme del laudo arbitral, ésta operaría con el agotamiento de los medios de impugnación que ofrece el ordenamiento respecto al laudo, o con el transcurso de los plazos sin que el titular del derecho de gravamen lo haya ejercido, cuestionando el

16 «Artículo 139.- Principios y derechos de la función jurisdiccional

Son principios y derechos de la función jurisdiccional:

1. La unidad y exclusividad de la función jurisdiccional. No existe ni puede establecerse jurisdicción alguna independiente, con excepción de la militar y la arbitral».

17 En esta sentencia, el Tribunal Constitucional señaló lo siguiente:

7. (...) el artículo 139, inciso 1 de nuestro ordenamiento constitucional consagra la naturaleza excepcional de la jurisdicción arbitral, lo que determina que, en el actual contexto, el justiciable tenga la facultad de recurrir al órgano jurisdiccional del Estado para demandar justicia, pero también ante una jurisdicción privada. (...)

11. Es justamente, la naturaleza propia de la jurisdicción arbitral y las características que la definen, las cuales permiten concluir a este Colegiado que no se trata del ejercicio de un poder sujeto exclusivamente al derecho privado, sino que forma parte esencial del orden público constitucional.

La facultad de los árbitros para resolver un conflicto de intereses no se fundamenta en la autonomía de la voluntad de las partes del conflicto, prevista en el artículo $2^{\circ}$ inciso 24 literal a de la Constitución, sino que tiene su origen y, en consecuencia, su límite, en el artículo $139^{\circ}$ de la propia Constitución.

18 «Artículo 59.- Efectos del laudo.

1. Todo laudo es definitivo, inapelable y de obligatorio cumplimiento desde su notificación a las partes».

19 ORMAZABAL, Guillermo. La ejecución de laudos arbitrales. Barcelona, J.M. Bosch, 1996, p. 47. 
laudo en los plazos previstos. Así, se pronuncia Ormazabal Sánchez al señalar:

(...) por cuanto cabe entender que, una vez interpuesto el recurso y resultando éste infructuoso o dejado transcurrir el tiempo en que puede eficazmente ser planteado, al resultar el laudo inimpugnable por los medios ordinarios previstos en la Ley arbitral (...), éste deviene firme ${ }^{20}$.

En este sentido, debemos mencionar que a través de la adopción de estos conceptos (consentida o ejecutoriada) no pretendemos «judicializar» al arbitraje, sino que consideramos que, al tratarse el arbitraje, también de un proceso, es posible aplicar dichos conceptos para poder referirnos a la firmeza del laudo arbitral.

En este sentido, debemos mencionar que a través de la adopción de estos conceptos (consentida o ejecutoriada) no pretendemos «judicializar» al arbitraje, sino que consideramos que, al tratarse el arbitraje, también de un proceso, es posible aplicar dichos conceptos para poder referirnos a la firmeza del laudo arbitral.

Pues bien, para determinar el carácter firme de un laudo arbitral, analizaremos cuáles son los recursos previstos en nuestra LA para su impugnación, luego de que éste es notificado a las partes.

Al respecto, la LA vigente -a diferencia de la anterior Ley General de Arbitraje ${ }^{21}$ - no contempla la posibilidad de una doble instancia a través de un recurso de apelación. Por tanto, no existe un recurso dentro del mismo arbitraje para impugnar el laudo.

Lo que se ha regulado en la LA, Decreto Legislativo No. 1071, son pedidos de rectificación, interpretación, integración y exclusión, que no pueden ser considerados como recursos o mecanismos para impugnar el laudo arbitral; toda vez que no cumplen con algunas de las características de los medios impugnatorios, como son la presencia de agravio y la identificación de error o vicio. Solo se tratan

${ }^{20}$ Ibid., p. 40.

21 «Artículo 60.- Recurso de Apelación.

Procede la interposición del recurso de apelación ante el Poder Judicial o ante una segunda instancia arbitral, cuando se hubiere pactado su admisibilidad en el convenio arbitral o si está previsto en el reglamento arbitral de la institución arbitral a la que las partes hubieran sometido su controversia. A falta de acuerdo expreso o en caso de duda, se entiende que las partes han pactado el recurso de apelación ante una segunda instancia arbitral.

El recurso de apelación tiene por objeto la revisión del laudo respecto de la apreciación de los fundamentos de las partes, de la prueba y, en su caso, aplicación e interpretación del derecho, y se resuelve confirmando o revocando total o parcialmente el laudo.

Contra los laudos de conciencia no procede recurso de apelación». 
de pedidos que buscan aclarar y/o corregir determinados extremos de la parte decisoria del laudo o que influyan en ella para determinar los alcances de la ejecución ${ }^{22}$, tanto así que una vez emitidas las decisiones que se pronuncian sobre estos pedidos, forman parte del laudo arbitral.

El único mecanismo de impugnación que se encuentra previsto en la LA es el de anulación que se plantea ante el Poder Judicial y solo para supuestos extraordinarios que contempla la ley y que no impiden la ejecución del laudo ${ }^{23}$, salvo que se otorgue una garantía para ello.

Una vez que se determine que el laudo arbitral es firme -sea porque transcurrió el plazo para interponer recurso de anulación o porque concluyó el proceso de anulación-, éste tendrá la autoridad de cosa juzgada, tal como lo señala Montero Aroca:

(...) las partes que acordaron el convenio arbitral y que, surgido el conflicto, lo sometieron a laudo, están subordinadas y obligadas a aceptar el tenor del fallo del laudo arbitral, que deviene en virtud de la cosa juzgada irrevocable. Por ello, pretendida por una de las partes la misma cosa frente a la otra, por la misma causa y en la misma calidad, se produciría el efecto de la cosa juzgada $(. . .)^{24}$.

Finalmente, debemos indicar que toda resolución firme puede ser ejecutable por las partes, en la medida que contenido sea «de condena», esto es que contenga una obligación de dar, hacer o no

22 Al respecto, Monroy Gálvez señala que la aclaración (o interpretación) no puede considerarse como recurso, porque se presenta cuando

(...) hay duda a lo que resuelve o hay forma oscuridad en lo que decide, es decir, o se puede entender en más de una forma o no se puede entender en ninguna. Precisamente tal configuración es la que permite asegurar que no es un recurso, dado que si no se sabe qué expresa no es posible alegar la presencia de agravio y, por la misma razón, tampoco es posible asegurar que se está ante un determinado vicio o error.

Por su parte, respecto al pedido de corrección (o rectificación), señala el mismo autor:

(...) permite que una resolución se complete y alcance a puntos que no fueron controvertidos pero de los cuales no se expresó decisión. (...); no comparte la naturaleza jurídica del error procesal, sino más bien del defecto formal en la redacción, es el caso del error numérico o el ortográfico.

En: MONROY, Juan. «Los medios impugnatorios en el Código Procesal Civil». Revista Ius Et Veritas, Año III, Núm. 5, pp. 258-259.

23 «Artículo 66.- Garantía de cumplimiento.

1. La interposición del recurso de anulación no suspende la obligación de cumplimiento del laudo ni su ejecución arbitral o judicial, salvo cuando la parte que impugna el laudo solicite la suspensión y cumpla con el requisito de la garantía acordada por las partes o establecida en el reglamento arbitral aplicable. Al examinar la admisión del recurso, la Corte Superior verificará el cumplimiento del requisito y, de ser el caso, concederá la suspensión.

2. Si no se ha acordado requisito alguno, a pedido de parte, la Corte Superior concederá la suspensión, si se constituye fianza bancaria solidaria, incondicionada y de realización automática en favor de la otra parte con una vigencia no menor a seis (6) meses renovables por todo el tiempo que dure el trámite del recurso y por una cantidad equivalente al valor de la condena contenida en el laudo (...) (énfasis nuestro)».

${ }^{24}$ MONTERO, Juan. Citado por MERINO, José y José Ma. CHILLÓN. Op. cit., p. 667. 
hacer; sin embargo, no toda resolución ejecutable (eficaz) tiene la calidad de firme; tal como sucede con la ejecución de los laudos arbitrales en nuestra legislación que pueden ser cuestionados vía recurso de anulación, o a través de un proceso de amparo, dependiendo de la afectación o del vicio que se considere se presenta en el laudo arbitral $^{25}$.

\section{i. Primer escenario para la calidad de firme: el laudo arbitral no es impugnado judicialmente}

En Analizando nuestra Ley de Arbitraje podemos observar que una vez que el laudo es notificado, es posible que las partes, dentro del plazo de quince (15) días planteen pedidos de rectificación, integración y exclusión del laudo, conforme al artículo $58^{26}$. De tal manera, que la resolución que se pronuncie sobre alguno de estos pedidos, formará parte del laudo.

${ }^{25}$ En relación a estos dos conceptos: eficacia y firmeza, la doctrina señala lo siguiente: Debe tenerse cuidado de no confundir la cosa juzgada con la ejecutoria (que sería la firmeza) de la sentencia. Ésta se cumple cuando no hay recursos pendientes por no otorgarlos la ley o por haber pasado el término para interponerlos, cualquiera que sea la sentencia; aquella (refiriéndose a la cosa juzgada) es una calidad especial que la ley les asigna a algunas sentencias ejecutoriadas. No hay cosa juzgada sin ejecutoria, pero si ésta sin aquella.

En: DEVIS ECHANDÍA, Hernando. Op. cit., pp. 523-524.

En igual sentido, Ormazabal Sánchez señala:

Lo que la firmeza y consiguiente autoridad de cosa juzgada viene pues, a añadir a tales efectos, es la irrevocabilidad y vinculación en relación con los órganos jurisdiccionales. Pero la sustantividad y existencia de los mismo puede pacíficamente concebirse sin necesidad de añadirse aquellas notas de irrevocabilidad y vinculatoriedad. Los efectos de la sentencia se producen, pues, ya desde que son definitivas o inalterables por el órgano jurisdiccional que las dictó. (...) la definitividad representa el momento inicial de la eficacia.

En: ORMAZABAL SÁNCHEZ, Guillermo. Op. cit., pp. 44- 47.

26 «Artículo 58.- Rectificación, interpretación, integración y exclusión del laudo.

1. Salvo acuerdo distinto de las partes o disposición diferente del reglamento arbitral aplicable:

a. Dentro de los quince (15) días siguientes a la notificación del laudo, cualquiera de las partes puede solicitar la rectificación de cualquier error de cálculo, de trascripción, tipográfico o informático o de naturaleza similar.

b. Dentro de los quince (15) días siguientes a la notificación del laudo, cualquiera de las partes puede solicitar la interpretación de algún extremo oscuro, impreciso o dudoso expresado en la parte decisoria del laudo o que influya en ella para determinar los alcances de la ejecución.

c. Dentro de los quince (15) días siguientes a la notificación del laudo, cualquiera de las partes puede solicitar la integración del laudo por haberse omitido resolver cualquier extremo de la controversia sometida a conocimiento y decisión del tribunal arbitral.

d. Dentro de los quince (15) días siguientes a la notificación del laudo, cualquiera de las partes puede solicitar la exclusión del laudo de algún extremo que hubiera sido objeto de pronunciamiento, sin que estuviera sometido a conocimiento y decisión del tribunal arbitral o que no sea susceptible de arbitraje.

(...)

2. La rectificación, interpretación, integración y exclusión formará parte del laudo. Contra esta decisión no procede reconsideración. (...) (énfasis nuestro)». 
Si la parte afectada con el laudo arbitral, no interpone recurso de anulación contra la resolución que se pronuncia por los pedidos del artículo 58 dentro del plazo de veinte (20) días previsto en el artículo 64 de la LA, entonces nos encontramos ante un laudo firme, que adquiere además la autoridad de cosa juzgada por haber quedado consentido, conforme a los términos del inciso 2) del artículo 59 de la misma Ley.

Independientemente del plazo de veinte (20) días para impugnar el laudo vía anulación, la parte beneficiada con esta decisión puede pedir su ejecución, la que debe verificarse en el plazo de quince (15) días. En tal sentido, la parte interesada podrá pedir la ejecución arbitral $^{27}$-de haberlo pactado- o judicial ${ }^{28}$ del laudo, dependiendo del caso concreto; ya que el cuestionamiento de laudo vía recurso de anulación no suspende su ejecución, salvo que se otorgue la garantía correspondiente.

\section{ii. Segundo escenario para la calidad de firme: el laudo arbitral es impugnado judicialmente}

El arbitraje puede ser definido como un mecanismo de resolución de conflictos, por el que las partes someten de forma voluntaria la solución de sus conflictos a los árbitros, comprometiéndose al cumplimiento de la decisión final que ellos adopten ${ }^{29}$.

27 «Artículo 67.- Ejecución arbitral.

1. A solicitud de parte, el tribunal arbitral está facultado para ejecutar sus laudos y decisiones, siempre que medie acuerdo de las partes o se encuentre previsto en el reglamento arbitral aplicable.

2. Se exceptúa de lo dispuesto en el numeral anterior, el caso en el cual, a su sola discreción, el tribunal arbitral considere necesario o conveniente requerir la asistencia de la fuerza pública. En este caso, cesará en sus funciones sin incurrir en responsabilidad y entregará a la parte interesada, a costo de ésta, copia de los actuados correspondientes para que recurra a la autoridad judicial competente a efectos de la ejecución».

28 «Artículo 68.- Ejecución judicial.

1. La parte interesada podrá solicitar la ejecución del laudo ante la autoridad judicial competente acompañando copia de éste y de sus rectificaciones, interpretaciones, integraciones y exclusiones y, en su caso, de las actuaciones de ejecución efectuada por el tribunal arbitral.

2. La autoridad judicial, por el solo mérito de los documentos referidos en el numeral anterior, dictará mandato de ejecución para que la parte ejecutada cumpla con su obligación dentro de un plazo de cinco (5) días, bajo apercibimiento de ejecución forzada.

3. La parte ejecutada sólo podrá oponerse si acredita con documentos el cumplimiento de la obligación requerida o la suspensión de la ejecución conforme al artículo 66. La autoridad judicial dará traslado de la oposición a la otra parte por el plazo de cinco (5) días. Vencido este plazo, resolverá dentro de los cinco (5) días siguientes. La resolución que declara fundada la oposición es apelable con efecto suspensivo.

4. La autoridad judicial está prohibida, bajo responsabilidad, de admitir recursos que entorpezcan la ejecución del laudo».

29 BULLARD, Alfredo. «Comentario al artículo 14 de la Ley de Arbitraje». En: Comentarios a la Ley Peruana de Arbitraje. Tomo I, Lima, IPA, p. 203. 
Dado que en todo proceso arbitral se deben respetar los Derechos Fundamentales (como es el derecho al debido proceso ${ }^{30}$ ), nuestro legislador ha previsto mecanismos de control posterior que garanticen su eficacia, evitando así situaciones de arbitrariedad o abusos del poder conferido a los árbitros.

Estos mecanismos de control, son ejercidos por instancias ajenas a los árbitros, como son el Poder Judicial (a través del proceso de anulación) y el Tribunal Constitucional (cuando actúa en última instancia a través del proceso de amparo), una vez concluido el arbitraje, a efectos que el agraviado revierta la decisión que le perjudica.

\section{a. El laudo es impugnado vía recurso de anulación}

En el caso que una de las partes del arbitraje considere que en el laudo arbitral se presenta una de las causales de anulación previstas en el artículo 63 de la LA ${ }^{31}$, podrá interponer el respectivo recurso de anulación.

Por su lado, Born, citando a Redfern y Hunter, define al arbitraje como un modo de resolución de controversias por una o más personas que derivan su poder de un acuerdo adoptado por las partes y cuya decisión es vinculante para ellas. Traducción libre de «A mode of resolving disputes by one or more persons who derive their power the agreement of the parties and whose decisions is binding upon them». En: BORN, Gary. International Commercial Arbitration. The Netherlands, Kluwer Law International, 2009, p. 217.

30 Al respecto, es útil citar la sentencia del Tribunal Constitucional recaída en el Expediente 6167-2005-PH/TC (Caso Cantuarias Salaverry):

9. Asimismo, la naturaleza de la jurisdicción independiente del arbitraje, no significa que se establezca el ejercicio de sus atribuciones con inobservancia de los principios constitucionales que informan la actividad de todo órgano que administra la justicia, tales como el de independencia e imparcialidad de la función jurisdiccional, así como los principios y derechos de la función jurisdiccional. En particular, en tanto jurisdicción, no se encuentra exceptuada de observar directamente todas aquellas garantías que componen el derecho al debido proceso.

31 «Artículo 63.- Causales de anulación.

1. El laudo sólo podrá ser anulado cuando la parte que solicita la anulación alegue y pruebe:

a. Que el convenio arbitral es inexistente, nulo, anulable, inválido o ineficaz.

b. Que una de las partes no ha sido debidamente notificada del nombramiento de un árbitro o de las actuaciones arbitrales, o no ha podido por cualquier otra razón, hacer valer sus derechos.

c. Que la composición del tribunal arbitral o las actuaciones arbitrales no se han ajustado al acuerdo entre las partes o al reglamento arbitral aplicable, salvo que dicho acuerdo o disposición estuvieran en conflicto con una disposición de este Decreto Legislativo de la que las partes no pudieran apartarse, o en defecto de dicho acuerdo o reglamento, que no se han ajustado a lo establecido en este Decreto Legislativo.

d. Que el tribunal arbitral ha resuelto sobre materias no sometidas a su decisión.

e. Que el tribunal arbitral ha resuelto sobre materias que, de acuerdo a ley, son manifiestamente no susceptibles de arbitraje, tratándose de un arbitraje nacional.

f. Que según las leyes de la República, el objeto de la controversia no es susceptible de arbitraje o el laudo es contrario al orden público internacional, tratándose de un arbitraje internacional.

g. Que la controversia ha sido decidida fuera del plazo pactado por las partes, previsto en el reglamento arbitral aplicable o establecido por el tribunal arbitral». 
Como es sabido, este recurso de anulación, tiene como objeto la revisión de validez del laudo por las causales taxativamente establecidas en el artículo 63. No pudiendo los jueces pronunciarse sobre el fondo de la controversia o sobre el contenido de la decisión, y tampoco podrán calificar los criterios, motivaciones o interpretaciones expuestas por el tribunal arbitral ${ }^{32}$.

Si bien la LA denomina a la anulación del laudo como recurso, doctrina mayoritaria ${ }^{33}$ así como el Tribunal Constitucional consideran que nos encontramos ante un proceso autónomo ${ }^{34}$. No obstante, más allá de la denominación, nos encontramos ante un mecanismo de impugnación del laudo, que puede determinar su nulidad por cuestiones formales.

Ahora bien, dado que la propia LA ha previsto la posibilidad de que -otorgándose una garantía (Carta Fianza bancaria)- el recurso de anulación suspenda los efectos del laudo durante el trámite del proceso judicial conforme a los términos del artículo 66 de la $\mathrm{LA}^{35}$,

32 Así, Chocrón Giráldez señala: «(...) el recurso de anulación no es una instancia más en la se haya de examinar el fondo del asunto, sino una vía para comprobar que el laudo no va contra el orden público y se ajusta a los puntos sometidos a decisión arbitral y a las normas básicas por las que se rige la institución». En: CHOCRÓN, Ana María. Los principios procesales en el arbitraje. Barcelona, Bosch, 2000, p. 211.

33 Según Lorca, cuando se solicita la nulidad de un laudo arbitral, «Lo que se inicia es un proceso de impugnación de la validez del laudo arbitral como una primera y única instancia que implicaría que, antes de la petición de anulación del laudo arbitral, no existe actividad jurisdiccional». En: LORCA, Antonio. La anulación del laudo arbitral. San Sebastián, DIJUSA-Instituto Vasco de Derecho Procesal. 2008, p. 55.

En igual sentido, se pronuncian HINOJOSA, Rafael. «La impugnación de laudo en la Ley de Arbitraje Española de 2003». En: Revista peruana de Arbitraje. Núm. 3, Lima, Grijley, 2006; CORDÓN, Faustino. Arbitraje y jurisdicción: algunas cuestiones polémicas. Madrid, Civitas, 2010; ALVA, Esteban. Arbitraje: la anulación de laudo. Lima, Estudio Mario Castillo Freyre-Palestra, 2011.

34 Así lo ha manifestado el Tribunal en el Caso Minera María Julia (Expediente No. 001422011-PA/TC), al haber calificado al recurso de anulación como una vía igualmente satisfactoria, en los términos del artículo 5.2. del Código Procesal Constitucional:

Este Colegiado estima que en tanto es posible que mediante el recurso de anulación de laudo resulte procedente revertir los efectos del pronunciamiento arbitral en los casos en los que éste involucre la afectación de derechos constitucionales, su naturaleza no es la de una vía previa es decir la de una instancia anterior al proceso constitucional, sino más bien, la de una vía procedimental igualmente satisfactoria, en los términos a los que se refiere el Artículo $5^{\circ}$ inciso 2) del Código Procesal Constitucional. En tales circunstancias quien acuda al recurso de anulación de laudo debe saber que lo que la instancia judicial ha de ser lo definitivo, sin que sea posible a posteriori acudir al proceso constitucional de amparo, ya que en este supuesto es de aplicación el inciso 3 del artículo $5^{\circ}$ del CPConst.

Refuerza la idea de un proceso autónomo e igualmente satisfactorio para la protección de los derechos constitucionales, la Duodécima Disposición Complementaria de la LA:

DUODÉCIMA: Acciones de garantía

Para efectos de lo dispuesto en el inciso 2 del artículo $5^{\circ}$ del Código Procesal Constitucional, se entiende que el recurso de anulación es una vía específica e idónea para proteger cualquier derecho constitucional amenazado o vulnerado en el curso del arbitraje o en el laudo.

35 «Artículo 66.- Garantía de cumplimiento.

1. La interposición del recurso de anulación no suspende la obligación de cumplimiento del laudo ni su ejecución arbitral o judicial, salvo cuando la parte que impugna el laudo 
ello confirma la tesis de que el laudo arbitral no se encuentra firme hasta la conclusión de dicho proceso.

Por tanto, una vez finalizado el proceso de anulación de manera definitiva (desestimando la pretensión anulatoria) ${ }^{36}$, nos encontraremos ante un laudo firme y con autoridad de cosa juzgada. Al respecto, Álvarez Rodríguez Señala:

(...) La firmeza del mismo (se refiere al laudo arbitral) se produce bien porque contra el mismo no se haya interpuesto el recurso de anulación, o bien porque interpuesto el mencionado recurso éste haya sido desestimado. El efecto que produce, como hemos apuntado, es de cosa juzgada, la cual deberá ser contemplada en su doble vertiente: como cosa juzgada formal, suponiendo que no es susceptible de ser atacada; y como cosa juzgada material, que impide que se abra un nuevo proceso sobre lo que ya ha sido juzgado por el/ los árbitro/s con tal de que exista una identidad de sujetos, objeto y actividad arbitral .concluida. Es decir, con este efecto se consagra la irrevocabilidad e inmutabilidad del laudo arbitral ${ }^{37}$.

Finalmente, consideramos pertinente citar la sentencia del Tribunal Constitucional recaída en el Expediente $\mathrm{N}^{\circ}$ 01064-2013-AA, del 25 de setiembre de 2013, respecto a lo que denominan «cosa juzgada arbitral», en el que se pronuncian respecto al plazo que tienen las partes para interponer el respectivo recurso de anulación y las consecuencias de su no interposición. Así, se señala:

22. Ello quiere decir que una vez vencido el plazo para solicitar la anulación del laudo, esto es, 10 días hábiles contados desde la notificación del laudo o de notificadas las correcciones, integración o aclaraciones del mismo (L.G.A.) o 20 días siguientes a la notificación, rectificación, interpretación, integración, exclusión del laudo (D.L.) el laudo es firme. Es pues a partir de este momento que el laudo no solo ha resuelto de modo definitivo la controversia, sino que lo ha hecho firmemente, no pudiendo volverse a plantear el conflicto ni ante un juez ni ante otro árbitro. Por lo tanto, el laudo tiene efecto tanto de cosa juzgada formal (lo que garantiza la inatacabilidad judicial del

solicite la suspensión y cumpla con el requisito de la garantía acordada por las partes o establecida en el reglamento arbitral aplicable. Al examinar la admisión del recurso, la Corte Superior verificará el cumplimiento del requisito y, de ser el caso, concederá la suspensión.

2. Si no se ha acordado requisito alguno, a pedido de parte, la Corte Superior concederá la suspensión, si se constituye fianza bancaria solidaria, incondicionada y de realización automática en favor de la otra parte con una vigencia no menor a seis (6) meses renovables por todo el tiempo que dure el trámite del recurso y por una cantidad equivalente al valor de la condena contenida en el laudo (énfasis nuestro)».

${ }^{36} \mathrm{Al}$ respecto, debe tenerse presente que el artículo 64, inciso 5) de la LA solo prevé la interposición del recurso de casación contra la resolución de la Corte Superior que declare la nulidad parcial o total del laudo impugnado.

37 Citado por Cantuarias. En: CANTUARIAS, Fernando. «Ejecución de Laudos Arbitrales dictados en el Perú». En: Derecho y Sociedad. Núm 25, 2005, p. 209. 
laudo), como de cosa juzgada material (lo que garantiza que no podrá dictarse un nuevo laudo o sentencia sobre lo que ha sido objeto del arbitraje). En suma, el laudo tiene efecto de cosa juzgada porque lo decidido por el árbitro o tribunal arbitral vincula a los jueces y a las partes del arbitraje. Esto configura la existencia, en sede arbitral, del derecho constitucional a que se respete un laudo que ha adquirido la autoridad de cosa juzgada arbitral, derecho éste que puede ser exigible ya sea en sede arbitral o en sede del Poder Judicial (énfasis nuestro).

23. En relación a este derecho, y haciendo un matiz para la jurisdicción arbitral, este Tribunal Constitucional considera que el derecho constitucional a que se respete un laudo que ha adquirido la autoridad de cosa juzgada arbitral, entre otros contenidos, «garantiza el derecho de toda parte arbitral, en primer lugar, a que los laudos que hayan puesto fin al proceso arbitral, y que no hayan sido impugnados oportunamente, no puedan ser recurridos posteriormente mediante medios impugnatorios o recursos, ya sea porque éstos han sido agotados o porque ha transcurrido el plazo para impugnarlos: y, en segundo lugar, a que el contenido de los laudos que hayan adquirido tales condiciones, no pueda ser dejado sin efecto ni modificado, sea por actos de otros poderes públicos, de terceros o, incluso, de los mismos árbitros que resolvieron el arbitraje en el que se dictó el laudo (Cfr., mutatis mutandis, STC N 04587-2004-AA/TC, fundamento 38) (énfasis nuestro).

Por tanto, compartimos la posición del Tribunal Constitucional.

\section{b. El laudo arbitral es impugnado vía proceso de amparo}

En relación a este mecanismo de impugnación, el Tribunal Constitucional estableció en un primer momento, que la anulación del laudo debía ser tratada como vía previa a efectos de interponer la correspondiente demanda de amparo ${ }^{38}$ (con lo cual se cuestionaba la resolución judicial emitida en el proceso de anulación conjuntamente con el laudo arbitral).

Luego, el Tribunal Constitucional estableció en la sentencia recaída en el caso PROIME (Expediente No. 04195-2006-PA/TC) que podía darse el caso que el recurso de anulación no constituya una vía previa respecto al proceso de amparo, respecto a las alegaciones

$38 \mathrm{Al}$ respecto, se puede observar lo mencionado por el Tribunal Constitucional en el caso Cantuarias Salaverry:

14. (...) El control judicial, conforme a ley, debe ser ejercido ex post, a posteriori, mediante los recursos de apelación y anulación de laudo previstos en la Ley General de Arbitraje. Por su parte, el control constitucional deberá ser canalizado conforme a las reglas establecidas en el Código Procesal Constitucional; vale decir que tratándose de materias de su competencia, de conformidad con el artículo 5, numeral 4 del precisado código, no proceden los procesos constitucionales cuando no se hayan agotado las vías previas. En ese sentido, si lo que se cuestiona es un laudo arbitral que verse sobre derechos de carácter disponible, de manera previa a la interposición de un proceso constitucional, el presento agraviado deberá haber agotado los recursos que la Ley General de Arbitraje prevé para impugnar dicho laudo. 
que podría tener la parte afectada con el laudo arbitral, las cuales no estaban directamente relacionadas con el derecho de defensa (causal de anulación prevista en el inciso 2) del artículo 73 de la Ley General de Arbitraje, Ley $N^{\circ}$ 26572).

Finalmente, a propósito de la sentencia recaída en el expediente No. 00142-2011-PA/TC (Caso Minera María Julia), el recurso de anulación constituye una vía paralela en la medida que a través de este proceso se pueden revertir los efectos de un pronunciamiento arbitral que afecte derechos constitucionales. Por tanto, más que una vía previa se debe considerar como una vía procedimental igualmente satisfactoria, en los términos a los que se refiere el artículo 5, inciso 2) del Código Procesal Constitucional.

En tales circunstancias, el amparo contra el laudo arbitral sería también un mecanismo de impugnación absolutamente excepcional, de control posterior del laudo, en los siguientes supuestos:

(i) Cuando se invoque la vulneración directa o frontal de precedentes vinculantes establecidos por el Tribunal Constitucional;

(ii) Cuando en el laudo se haya ejercido control difuso de una norma cuya constitucionalidad ha sido declarada por el Tribunal Constitucional; $\mathrm{y}$,

(iii) Cuando el amparo sea interpuesto por un tercero que no forma parte del convenio arbitral, por la afectación directa y manifiesta de sus derechos constitucionales.

Si fuera el caso que una de las partes se encontrara en alguno de los supuestos antes mencionados, podría interponer demanda de amparo contra el laudo arbitral, en el plazo de sesenta (60) días hábiles, conforme a lo previsto en el artículo 44 del Código Procesal Constitucional $^{39}$. En ese escenario, solo nos encontraríamos ante un laudo firme, en el caso que se declarara infundada la demanda de amparo por la Corte Superior que conozca dicho proceso. Es en ese momento, que el laudo adquirirá la autoridad de cosa juzgada.

39 «Artículo 44.- Plazo de interposición de la demanda

El plazo para interponer la demanda prescribe a los sesenta días hábiles de producida la afectación, siempre que el afectado hubiese tenido conocimiento del acto lesivo y se hubiese hallado en posibilidad de interponer la demanda. Si esto no hubiese sido posible, el plazo se computará desde el momento de la remoción del impedimento.

Tratándose del proceso de amparo iniciado contra resolución judicial, el plazo para interponer la demanda se inicia cuando la resolución queda forme. Dicho plazo concluye treinta días hábiles después de la notificación de la resolución que ordenase cumpla lo decidido (...)». 


\section{Conclusiones}

Luego del análisis efectuado, podemos arribar a las siguientes conclusiones.

4.1 El artículo 59 de la LA regula los efectos del laudo y su ejecución. Sin embargo, estos no son coincidentes con el momento en el que un laudo arbitral tiene la calidad firme y, por tanto, es pasible de adquirir la autoridad de la cosa juzgada.

4.2 Las decisiones jurisdiccionales (judiciales y arbitrales) son decisiones definitivas en la medida que resuelven el conflicto sometido por las partes.

4.3 Estas decisiones son susceptibles de ser cuestionadas a través de los medios impugnatorios a ser empleados al interior del mismo proceso o por medio de mecanismos autónomos -procesos con contenido impugnatorio- previstos excepcionalmente por el ordenamientojurídico. A ese periodo en el que se pueden cuestionar por el titular del derecho, se le denomina periodo de gravamen.

4.4 Las decisiones jurisdiccionales adquieren la calidad de firmes, una vez que se presente una de estas dos situaciones: (i) la parte perjudicada con la decisión ha agotado todos los mecanismos para cuestionarla dentro del proceso (resolución ejecutoriada), o (ii) dicha parte ha dejado transcurrir el plazo para impugnar la decisión sin haber presentado el recurso respectivo (resolución consentida).

4.5 Una vez que la decisión jurisdiccional es firme, ésta adquiere la autoridad de cosa juzgada, deviniendo en inmutable.

4.6 En el caso del laudo arbitral, este adquiere la calidad de firme cuando no se ha interpuesto el recurso de anulación previsto en el artículo 62 de la LA, o habiéndose utilizado este mecanismo de impugnación se emitió la decisión que pone fin al cuestionamiento.

De otro lado, en base a lo previsto en el Código Procesal Constitucional y al precedente del Tribunal Constitucional en el Caso Minera María Julia (Expediente No. 00142-2011-PA/TC), un laudo arbitral será firme si no ha sido cuestionado a través del proceso de amparo, en el plazo de sesenta (60) días hábiles, en los tres (3) supuestos previstos expresamente en dicha decisión del, o habiéndose interpuesto la demanda de amparo se emite una 
decisión que pone fin a este proceso constitucional con contenido impugnatorio.

4.7 En el caso que la parte notificada con el laudo, plantea algún pedido de rectificación, interpretación, integración y/o exclusión del laudo, y luego de ello, no interpone el recurso de anulación, se entenderá que el laudo queda firme con la notificación de la resolución que resuelve los pedidos antes indicados.

4.8 En tal sentido, consideramos que si las partes, por ejemplo, han pactado que las garantías otorgadas antes del inicio del arbitraje permanecerán hasta que la decisión quede firme; esto implicaría que dicha decisión adquiera la autoridad de cosa juzgada, en función a los dos (2) escenarios anteriormente descritos. 